\title{
PRESENTATION OF RETINOBLASTOMA AT A PAEDIATRIC EYE CLINIC IN GHANA
}

\author{
V. ESSUMAN ${ }^{1}$, C. T. NTIM-AMPONSAH ${ }^{1}$, S. AKAFO $^{1}$, L. RENNER $^{2}$ and L. EDUSEI ${ }^{3}$ \\ 1Ophthalmology Unit, Department of Surgery, ${ }^{2}$ Department of Child Health, and ${ }^{3}$ Department of Pathology \\ University of Ghana Medical School, PO Box 4236, Accra, Ghana
}

Corresponding Author: Dr. Vera Essuman

E-mail:vadessuman@yahoo.com

Conflict of interest: None declared

\section{SUMMARY}

Background: Retinobalstoma, the commonest childhood malignant intraocular tumour, is usually diagnosed early with over $90 \%$ survival rate in developed countries. In developing countries, the diagnosis is late resulting in less than $50 \%$ survival.

Objective: To determine retinoblastoma stages at presentation and patients' outcomes.

Design: Retrospective case series.

Methods: The clinical and histopathological records of children with retinoblastoma seen from May 2004 to December 2005 were studied. Data was analysed for mode of presentation, laterality, clinical staging using Reese-Ellsworth (R-E) classification, histopathological high risk features (HHRF) for metastasis, and patient outcome.

Setting: Ophthalmology Unit, Korle-Bu Teaching Hospital, Ghana.

Results: Twenty-three patients presented with retinoblastoma over the period. Males were 12(52.2\%). The age range from 1 to 84 months, mean $36.3( \pm 22.15)$ and median (36 months). Nineteen $(82.6 \%)$ had unilateral and $4(17.4 \%)$ bilateral disease. The common clinical presentations were leukocoria in 20(87.0\%), proptosis $8(34.8 \%)$, strabismus $5(21.7 \%)$ and red eye $5(21.7 \%)$. The clinical features were commensurate with R-E stage V in 20(87.0\%) patients, 2(8.7\%) with orbital recurrence and $1(4.3 \%)$ with post-enucleation anophthalmos. HHRFs were present in 9(75\%) enucleated eyes with invasion of optic nerve as the commonest site (7/9). The patients were followed up for 1 day to 19 months. Eight abandoned treatment, 2 were discharged for palliative treatment, 2 out of 5 with metastasis died and 6 had no metastases at their last visit. Common sites for metastasis were the bone marrow, brain and orbit.

Conclusion: Majority of the patients presented with advanced disease manifesting as leukocoria, proptosis, $\mathrm{RE}$ stages $\mathrm{V}$ disease and poor outcome.

Keywords: leukocoria, metastasis,Reese-Ellsworth, retinoblastoma, tumour.

\section{INTRODUCTION}

Retinoblastoma is the commonest intraocular tumour in childhood affecting about 1 child in $20,000{ }^{1}$ It accounts for about $3 \%$ of cancers in children younger than 15 years of age. ${ }^{1}$ Untreated, retinoblastoma is almost uniformly fatal, ${ }^{2}$ but with availability of resources for early detection and treatment, the survival rate has improved from approximately $30 \%$ in the 1930 s to over $90 \%$ in the $1990 \mathrm{~s}$ in developed countries. ${ }^{3,4,5,6}$ However, in developing countries, the majority of patients with retinoblastoma present with advanced disease with the resultant 5 year survival of less than $50 \%$. $^{7,8,9}$

The factors for this poor prognosis may include late presentation with a high mean age at diagnosis, 10,11 interval between onset and treatment of more than 5 months, a lag time before treatment exceeding 2.5 months, extraocular disease, ${ }^{12}$ higher occurrence of poorly differentiated tumours, ${ }^{13}$ presence of other histopathological high risk features (HHRF) for metastasis, and other factors such as lack of knowledge about the disease and its outcome, high costs of hospital care (diagnosis and treatment), and lack of resources for care. Improvement in survival in developing countries will require measures that enhance early reporting through health education, ${ }^{14}$ early and cheaper means of screening those at risk and early diagnosis of affected patients, as well as early, affordable and effective forms of treatment including means of funding such as national health insurance or government- funded schemes. ${ }^{15,16,17}$

At the Paediatric Department of Ghana's premier teaching hospital, Korle Bu Teaching Hospital, Accra, retinoblastoma was found to be the second commonest childhood tumour after Burkitt's lymphoma. ${ }^{18}$ Retinoblastoma was the commonest malignant intraocular childhood cancer seen at the Eye Clinic of the same hospital, and as elsewhere, and formed about $50 \%$ of ocular tumours seen at the clinic. ${ }^{19}$ Only about $38 \%$ of the retinoblastomas were diagnosed before the age of 3 years. ${ }^{19}$ 
Unfortunately over a decade after this study, anecdotal observations showed that children with retinoblastoma attending the same clinic were increasingly presenting late with advanced disease and fatal outcomes and there had been no active intervention to address this trend.

As survival in patients with retinoblastoma is inversely related to the stage of the disease at presentation, ${ }^{20-24}$ we carried out this study to determine the stages of retinoblastoma in our patients at presentation and their relation to outcome. This will serve as baseline data for further studies and help plan interventions for improvement in survival.

\section{MATERIALS AND METHOD}

A retrospective case series of all children seen at the Korle-Bu Teaching Hospital Eye unit with a diagnosis of retinoblastoma, from May 2004 to December 2005, was determined from clinical and histopathological records of the hospital. Data was compiled on demographic characteristics, clinical examinations, investigations, histopathology findings, treatment given and their outcomes. The information was recorded on pre-designed forms.

The initial evaluation of the children included complete ophthalmological and systemic examination in collaboration with the Paediatric Oncology Unit. The ophthalmological evaluation included visual acuity, slit lamp examination and dilated-fundus examination with scleral indentation under general anaesthesia. The systemic evaluation included full blood count, lumbar puncture for cerebrospinal fluid (CSF) cytological analysis, bone marrow aspirations for tumour cells, chest x-rays and examination for other evidence of metastases.

The basis of diagnosis of retinoblastoma was: a leukocoria associated with a retinal mass, with chalky areas, blood vessels coursing over it, with or without subretinal fluid, and or a proptosis preceded by a history of a 'cat's eye' or a shiny white spot in the eye. This was with or without confirmation by imaging studies i.e. C.T. scan or ultrasonography, looking for presence of calcifications in an intraocular mass arising from the retina. The clinical diagnosis could not be confirmed by imaging studies in some patients as they were not affordable to their carers. Treatment given included enucleation alone, chemotherapy and enucleation, or combined chemotherapy, enucleation and external beam radiation. Chemotherapy included vincristine, etoposide, carboplatin or cyclophosphamide and intrathecal methotrexate when indicated according to a local protocol.
Data was analysed for mode of presentation, laterality, clinical staging of disease using Reese-Ellsworth (R-E) classification (Box 1), presence of HHRF for metastasis in enucleated eyes and patient outcome.

Box1 Reese-Ellsworth Classification for Retinoblastoma $^{25}$

\begin{tabular}{|l|l|}
\hline Group I & $\begin{array}{l}\text { a. Solitary tumor, less than 4 disc diame- } \\
\text { ters in size, at or behind the equator } \\
\text { b. Multiple tumors, none over 4 disc di- } \\
\text { ameters in size, all at or behind the equa- } \\
\text { tor. }\end{array}$ \\
\hline Group II & $\begin{array}{l}\text { a. Solitary tumour, 4 to 10 disc diame- } \\
\text { ters in size, at or behind the equator. } \\
\text { b. Multiple tumors, 4 to 10 disc diame- } \\
\text { ters in size, all at or behind the equator. }\end{array}$ \\
\hline Group III & $\begin{array}{l}\text { a. Any lesion anterior to the equator. } \\
\text { b. Solitary tumor larger than 10 disc di- } \\
\text { ameters in size behind the equator. }\end{array}$ \\
\hline Group IV & $\begin{array}{l}\text { a. Multiple tumors, some larger than 10 } \\
\text { disc diameters. } \\
\text { b. Any lesion extending anterior to the } \\
\text { ora serrata. }\end{array}$ \\
\hline Group V & $\begin{array}{l}\text { a. Massive tumors involving over half } \\
\text { the retina. } \\
\text { b. Vitreous seeding. }\end{array}$ \\
\hline
\end{tabular}

HHRF were uveal infiltration involving the iris, ciliary body or choroid, anterior chamber seeding, scleral or extra scleral infiltration and optic nerve invasion i.e. lamina cribrosa, retrolaminar or transection margin of optic nerve.

Patient outcome was defined as alive with metastases, without metastases or with second malignant neoplasm; or dead with metastases, with second malignant neoplasm or from other causes.

\section{RESULTS}

Twenty-three patients were seen with retinoblastoma within this 20 month period. The male:female ratio was 1.1:1. The age ranged from 1 to 84 months, with a mean of $36.3( \pm 22.15)$ months and median of 36 months. Nineteen $(82.6 \%)$ patients had unilateral and $4(17.4 \%)$, including a neonate, had bilateral disease. There was no trilateral retinoblastoma seen ). With regards to the bilateral cases, the parents of only one patient could be examined in an attempt to determine the inheritance pattern. They had normal ocular findings. The parents of the other 3 children abandoned treatment of their children as soon as the diagnoses were confirmed and counseling on the disease and its management offered. Hence the inheritance pattern could not be ascertained. 
The common presentations were leukocoria 20 $(87.0 \%)$, proptosis $8(34.8 \%)$, strabismus $5(21.7 \%)$ and red eye $5(21.7 \%)$. Other presentations included fungating and necrotic orbital mass 2 (8.7\%), buphthalmos with enlarged and cloudy cornea $2(8.7 \%)$ flat anterior chamber $3(13.1 \%)$, rubeosis $1(4.4 \%)$, and hyphaema $1(4.4 \%)$.

Table 1 Baseline Characteristics of Patients with Retinoblastoma

\begin{tabular}{|c|c|}
\hline Total number & 23 \\
\hline \multicolumn{2}{|c|}{ Interval between enucleation \& metastasis (mths) } \\
\hline Range, Mean, SD & $0.2-7,5.72,2.71$ \\
\hline \multicolumn{2}{|l|}{ Investigations } \\
\hline $\begin{array}{l}\text { CT Scan confirmation of } \\
\text { diagnosis }(n=13) \\
\text { - intraocular } \\
\text { - extraocular (Optic Nerve.\& } \\
\text { Brain) }\end{array}$ & $\begin{array}{l}9(69.2 \%) \\
4(30.8 \%)\end{array}$ \\
\hline $\begin{array}{l}\text { Ultrasonography (B mode) } \\
\text { - intraocular } \quad(n=1)\end{array}$ & 1 \\
\hline Bone Marrow infiltration $(\mathrm{n}=7)$ & $4(57.1 \%)$ \\
\hline CSF (normal) $(n=4)$ & $4(100 \%)$ \\
\hline \multicolumn{2}{|c|}{ Initial Treatment given 12 patients } \\
\hline Primary enucleation & $7(58.3 \%)$ \\
\hline Chemoreduction +Enucleation & $4(17.4 \%)$ \\
\hline $\begin{array}{l}\text { Chemoreduction + Euncleation } \\
+ \text { EBRT }\end{array}$ & $1(4.3 \%)$ \\
\hline \multicolumn{2}{|c|}{$\begin{array}{l}\text { Histopathological High Risk Features (in } 12 \text { enu- } \\
\text { cleated eyes) }\end{array}$} \\
\hline Presence of risk factors & $9(75 \%)$ \\
\hline Unknown & $1(8.3 \%)$ \\
\hline No Risk Factors & $2(16.7 \%)$ \\
\hline
\end{tabular}

Twenty patients $(87.0 \%)$ presented with R-E stages V: 3 with $\mathrm{Va}, 11$ with $\mathrm{Vb}$ and 6 with $\mathrm{Vb}$ with orbital inflammation or extension; $2(8.7 \%)$ others presented with orbital recurrence and 1 (4.3\%) with postenucleation anophthalmos after treatment elsewhere with histology proven diagnosis.

Results of investigations for confirmation of diagnosis and for metastases are as illustrated in Table 1.
One or more HHRF for metastasis were present in 9 $(75 \%)$ of the 12 enucleated eyes: invasion of optic nerve 4 including 1 transection margin, uveal infiltration 1, combined optic nerve and uveal infiltration 2, extra-scleral and orbital fat extension 1, and combined extra-scleral, uveal and optic nerve invasion 1 .

Seven of the enucleations were primary, for clinical diagnoses and treatment of intraocular retinoblastoma. Four of these showed HHRFs: invasion of optic nerve 2 , uvea 1, combined uvea and optic nerve 1 . One patient whose histopathology report and specimen could not be traced, and also defaulted from follow up shortly after surgery, presented 9 months post surgery with orbital recurrence.

The patients were followed up for 1 day to 19 months, mean $5.7(\mathrm{SD} \pm 5.67)$ and mode of 8 months. At the last follow up, which was variable, 6 alive were patients with no metastasis while 5 had metastasis. At followup periods of 3 and 6 months, 3 patients were alive including 1 with metastasis; at 12 months only 1 was alive without metastasis and at 18 months only one was alive with metastasis. Parents/carers of eight $(34.8 \%)$ patients defaulted treatment, $2(8.7 \%)$ were discharged home on account of advanced disease with financial difficulty for palliative care at peripheral hospitals near their residential areas and $2(8.7 \%)$ died with metastasis at 4 and 13 months respectively. No second malignant tumour was seen (Table2).

The commonest site for metastasis was the bone marrow - 4 out of the total number of 7 patients who had metastasis ( 5 who were alive with metastasis and 2 who died with metastasis). Other sites were the brain/CNS 2, orbit 2, and combined brain and orbit 1 . One child with brain metastasis also showed metastases to the skull.

\section{DISCUSSION}

This study showed that majority of the patients $(82.6 \%)$ presented with unilateral retinoblastoma. This conforms with studies from both developed and developing countries although this proportion seems higher in our small series., ${ }^{9,10,16}$ The mean age of diagnosis was high at 36.3 months. This finding confirms observations from other developing countries in Africa and the Asia. ${ }^{9,10,20}$ A higher mean age at diagnosis has been found to be associated with advanced or metastatic retinoblastoma. ${ }^{21}$ This is in sharp contrast with the findings from developed countries, where the mean age of diagnosis is less than 24 months. 5 
Table 2 Outcome in 23 patients with retinoblastoma

\begin{tabular}{|c|c|c|c|c|c|}
\hline $\begin{array}{l}\text { Duration of fol- } \\
\text { low up (months) }\end{array}$ & $\begin{array}{c}\text { Total number of } \\
\text { patients } \\
\text { No. }(\%)\end{array}$ & $\begin{array}{c}\text { Alive } \\
\text { Without } \\
\text { metastases } \\
\text { No. }(\%)\end{array}$ & $\begin{array}{c}\text { Alive } \\
\text { with } \\
\text { metastases } \\
\text { No. }(\%)\end{array}$ & $\begin{array}{c}\text { Defaulted/ } \\
\text { Discharged } \\
\text { No. }(\%)\end{array}$ & $\begin{array}{c}\text { Dead } \\
\text { With metastases } \\
\text { No. }(\%)\end{array}$ \\
\hline$<3$ & $8(34.8)$ & $1(4.3)$ & $2(8.7)$ & $5(21.7)$ & \\
\hline 3 & $6(26.1)$ & $2(8.7)$ & $1(4.3)$ & $2(8.7)$ & $1(4.3)$ \\
\hline 6 & 5 (21.7) & $2(8.7)$ & $1(4.3)$ & $2(8.7)$ & \\
\hline 12 & $2(8.7)$ & $1(4.3)$ & & & $1(4.3$ \\
\hline 18 & $2(8.7)$ & & $1(4.3)$ & $1(4.3)$ & \\
\hline & $23(100)$ & $6(26.1)$ & $5(21.7)$ & $10(43.5)$ & $2(8.7)$ \\
\hline
\end{tabular}

The common clinical presentations of leukocoria, proptosis squint and red eye from this study are also comparable to those in other developing countries. $^{10,11,22-24}$ These features together with other signs such as, secondary glaucoma, fungating mass, hyphaema and flattened anterior chamber are known signs of advanced disease or high risk for metastasis. $^{2,23}$ A study of 29 patients in Congo revealed the common presenting signs to be leukocoria, $49 \%$, followed by proptosis $(28 \%)$. Other signs were strabismus, red eye, anterior scleral staphyloma, hyphema and buphthalmia. ${ }^{11}$ In Kenya, an analysis of 470 oculo-orbital tumours demonstrated proptosis to be the hallmark, and the commonest manifestation at first attendance of orbital disease, with retinoblastoma being an important cause and that its presence depicted late or advanced disease. ${ }^{22}$ These studies show that proptosis, a late sign, is a common presentation of retinoblastoma in developing countries compared with the developed world ${ }^{11,22,24}$, a fact that validates the late or advanced presentation of most of our patients.

A study in New Delhi, India, which reviewed 392 patients with retinoblastoma, found all of them at presentation to have R-E grade $\mathrm{V}$ retinoblastoma, which represents advanced disease. ${ }^{24}$ Sahu et al in their retrospective study of 296 affected patients with retinoblastoma, over an 8 years period, in Mumbai, India, also found a predominance of advanced-stage disease with $74.5 \%$ presenting with Reese-Ellsworth group IV and V disease. ${ }^{20}$ These findings are supported by our study.

In Saudi Arabia, a study which assessed the value of various tests including bone marrow aspiration, lumbar puncture, and radionuclide scans, as part of the initial workup for metastases, found only $9.9 \%$ of the 101 patients who had bone marrow studies with tumour infiltration, and $4.3 \%$ of the 94 patients with lumbar punctures yielding positive results. ${ }^{27}$ The rate of bone marrow metastasis is relatively high in our study, but this may be due to the small numbers in our study therefore we cannot make any meaningful comparison with this lager series from Saudi Arabia. Similarly, the percentage of our patients who had CSF analysis, or CT imaging is too small to allow any meaningful comparison. The lack of confirmation of diagnoses with imaging studies and the inability to have full metastatic work-up for some of the patients, due to financial difficulties was also a significant limitation on final diagnoses and extent of tumour metastases. Consistent systematic investigations will be required in the future to allow such comparisons.

Optic nerve, choroid, extra scleral and anterior chamber infiltration are all recognized HHRFs for metastasis. ${ }^{26-32}$ Seventy-five percent of enucleated eyes in our series had one or more HHRF for metastasis. Optic nerve invasion was the commonest site of extraocular invasion in our series and correlates with that in other studies. ${ }^{10}$

Our study has added to the importance of subjecting all enucleated eyes for histopathological analysis in order to identify those with HHRFs, the presence of which have adverse predictive value on prognosis. ${ }^{26-31}$

Progressively small numbers of patients continued with follow up thus for 12 and 18 months durations there were only 1 without metastasis and 1 with metastasis respectively. 
This was also reflected in more than a third of the patients either abandoning treatment, 34.8\%, or discharged with advanced disease and financial difficulty $(8.7 \%)$, the latter group for palliative care at peripheral hospitals near their homes. In Honduras, a study assessing the impact of public education on the late diagnosis of retinoblastoma was carried out from July 1995 to January 2005. The study showed that the proportion of patients diagnosed with advanced retinoblastoma i.e. with extra-ocular disease, declined from $73 \%$ of the 59 diagnosed cases during the eight previous years (July 1995-June 2003) before the campaign, to only $35 \%$ of the 23 diagnosed cases during the post-campaign period (June 2003-January 2005), $(P=0.002)$. However, more than one-third of patients in both time periods either refused therapy or abandoned treatment. ${ }^{33}$ This high default rate identifies with our study.

We do acknowledge the limitations of this study. The small numbers analysed makes it difficult comparing our results with those from centres with larger series; similarly, it is impossible to make inferences for the whole population from this series. However the importance of the disease, being both sight and life threatening, renders the findings significant. Secondly, our centre is the only tertiary hospital in Ghana with a paediatric eye unit and thus the final referral point. This could explain the reason for all the patients encountered being those with advanced disease. Other general ophthalmologists in smaller or peripheral hospitals manage the less complicated cases by enucleation. This is because caretakers of the affected children sometimes refuse referrals to the bigger hospitals on account of long distance and cost. (Essuman V. Conversation with General Ophthalmologists: Regional Eyecare Planning Workshop, Accra, 12 $2^{\text {th }}$ May 2005).

Ghana has a population of about 22 million, with $41 \%$ (i.e. 9 million) being children less than 15 years. Using a similar retinoblastoma age-standardized rate (ASR) from Nigeria (7.4/million: IARC,1998) which shares similar geographic and demographic features in the West African Sub-region, implies that about 67 new cases of retinoblastoma should be seen in Ghana each year, of whom only 14 get to the Eye Unit of Korle-Bu each year (23 in 20 months). This suggests that about 53 children per annum with retinoblastoma do not get to the tertiary centre at Korle-Bu. These patients may seek treatment from general ophthalmologists in the periphery or from alternate medical practitioners such as traditional healers and spiritualists.
It is of great interest to know how many of them get treatment in peripheral eye hospitals and the magnitude of retinoblastoma in the country. This requires further studies. A national register of childhood tumours, including retinoblastoma will be helpful.

In conclusion, majority of the patients presented with advanced disease manifesting as leukocoria, proptosis, $\mathrm{R}-\mathrm{E}$ stages $\mathrm{V}$ disease and poor outcome. These findings have highlighted the late stage of presentation of patients with retinoblastoma in our hospital, problems with default and funding of treatment. Further studies are needed into: why they present late, the high default rate, ways of improving early reporting, cheaper ways of funding treatment, the magnitude of retinoblastoma in the country and how many of them seek treatment at peripheral hospitals from general ophthalmologists, in order to improve on survival.

\section{ACKNOWLEDGEMENTS}

We are grateful to Professor W. Amoaku and $\mathrm{Mr}$ Thomas Ndanu for editing the script, Mrs. Dorothy Fiadoyor and Mr Ben Abaidoo who helped in diverse ways with the data compilation.

\section{REFERENCES}

1. Donaldson SS, Egbert PR and Lee WH Retinoblastoma. In: PizzoPA and Poplack DG: Principles and Practice of Pediatric Oncology. Philadelphia: JB Lippincott. 2nd ed. 1993. pp 683696.

2. Gunduz K, Muftuoglu O, Gunalp I, Unal E, Tacyildiz N: Metastatic retinoblastoma clinical features, treatment, and prognosis. Ophthalmology. 2006 Sep; 113 (9):1558-66.

3. Abramson DH, Niksarli K, Ellsworth, Servodidio CA: Changing trends in the management of retinoblastoma: 1951-1965 vs 1966-1980. J Pediatr Ophthalmol Strabismus 1994,31:32-37

4. Shields JA, Shields CL: Current management of Retinoblastoma. Mayo Clin Proc 1994, 69: 5056.

5. MacCarthy A, Draper GJ, Steliarova-Foucher E, Kingston JE: Retinoblastoma incidence and survival in European children (1978-1997). Report from the Automated Childhood Cancer Information System project Eur J Cancer. 2006 Sep; 42 (13):2092-102

6. Berman EL, Donaldson CE, Giblin M, Martin FJ. Outcomes in retinoblastoma, 1974-2005: the Children's Hospital, Westmead: Clin Experiment Ophthalmol. 2007 Jan-Feb;35(1):5-12.

7. Ajaiyeoba IA, Akang EE, Campbell OB, Olurin IO, Aghadiuno PU: Retinoblastomas in Ibadan: 
treatment and prognosis. West Afr $J$ Med 1993 Oct-Dec;12 (4):223-7.

8. Bowman RJ, Mafwiri M: Outcome of retinoblastoma in east Africa. Pediatr Blood Cancer 2006 Nov 21

9. Moukouri EN, Mc Moli T, Mba S :Epidemiologic aspects of retinoblastoma in a tropical region (Yaounde-Cameroun). Rev Int Trach Pathol Ocul Trop Subtrop Sante Publique 1994:95-101.

10. Akang E E, et al: Retinoblastomas in Ibadan Nigeria II- Clinicopathological features. West Afri J Med 2000,19 6-11

11. Akimbo $\mathrm{W}$ A et al: Presenting signs of Retinoblastoma in Congolese patients, Bull Soc Belge Ophthalmol. 2002; 283 37-41.

12. Chang CY et al,: Retinoblastoma in Taiwan: survival rate and prognostic factors. Jpn $J$ Ophthalmol. 2006 May-Jun; 50 (3):242-9.

13. Mukhtara U \& Kagame K. Pathological study of retinoblastoma in Mbara, Uganda. The central African Journal of Medicine, 46 (1) 2000 13-16.

14. Leander $\mathrm{C}, \mathrm{Fu} \mathrm{LC}$ et al: Impact of an education program on late diagnosis of retinoblastoma in Honduras. Pediatr Blood Cancer. 2006 Sep 28; [Epub ahead of print]

15. Su WW, Kao LY: Retinoblastoma in Taiwan: the effect of a government-sponsored national health insurance program on the treatment and survival of patients with retinoblastoma. $J$ Pediatr Ophthalmol Strabismus 2006 Nov-Dec;43 (6):358-62.

16. Ozkan A, Pazarli H: Retinoblastoma in Turkey: survival and clinical characteristics 1981-2004. Pediatr Int. 2006 Aug;48(4):369-73.

17. Klauss V and Adala H.S: Traditional herbal eye medicine in Kenya. World Health Forum 1994; 15: $138-142$

18. Welbeck JE, Hesse AA. Pattern of childhood malignancy in Korle $\mathrm{Bu}$ Teaching Hospital, Ghana. West Afr J Med. 1998 Apr-Jun;17(2):81-4.

19. Ntim-Amponsah C.T Ocular Tumours and problems with Management: A Ghanaian experience. East African medical Journal. March 7, 1996: 182-186.

20. Sahu S, Banavali SD, Pai SK, Nair CN, Kurkure PA, Motwani SA, Advani SH. Retinoblastoma: problems and perspectives from India. Pediatr Hematol Oncol. 1998 Nov-Dec;15(6):501-8.

21. Gunduz K, Muftuoglu O, Gunalp I, Unal E, Tacyildiz N: Metastatic retinoblastoma clinical features, treatment and prognosis. Ophthalmology. 2006 Sep;113 (9):1558-66.

22. Klauss V, Chana HS: Ocular tumors in Africa. Soc Sci Med. $1983 ; 17$ (22):1743-50.

23. Saiju R, Thakur J, Karmacharya PC, Shah DN: Retinoblastoma in Nepal: a clinical profile of 30 cases. Nepal Med Coll J. 2006 Sep;8(3):171-5.

24 Balasubramanya R, Pushker N, Bajaj MS, Ghose S, Kashyap S, Rani A.: Atypical presentations of retinoblastoma. J Pediatr Ophthalmol Strabismus. 2004 Jan-Feb; 41(1):18-24.

25. Reese AB: Tumours of the eye, NewYork, 1976,Harperand Row Pub., Inc.

26. Messmer EP, Heinrich T, Hopping W, de Sutter E, Havers W, Sauerwein W.: Risk factors for metastases in patients with retinoblastoma. Ophthalmology. $1991 \mathrm{Feb}$;98(2):136-41.

27. Karcioglu ZA, al-Mesfer SA, Abboud E, Jabak MH, Mullaney PB.: Workup for metastatic retinoblastoma. A review of 261 patients. Ophthalmology. 1997 Feb;104(2):307-12.

28. Khelfaoui F, Validire P, Auperin A, Quintana E, Michon $\mathrm{J}$, et al: Histopathologic risk factors in retinoblastoma: a retrospective study of 172 patients treated in a single institution. Cancer. 1996 Mar 15;77(6):1206-13.

29. Shields CL, Shields JA, Baez K, Cater JR, De Potter P.: Optic nerve invasion of retinoblastoma. Metastatic potential and clinical risk factors. Cancer. 1994 Feb 1;73(3):692-8.

30. Shields CL, Shields JA, Baez KA, Cater J, De Potter PV.: Choroidal invasion of retinoblastoma: metastatic potential and clinical risk factors. $\mathrm{Br} J$ Ophthalmol. 1993 Sep; 77(9):544-8.

31. Messmer EP, Heinrich T, Hopping W, de Sutter E, Havers W, Sauerwein W.: Risk factors for metastases in patients with retinoblastoma. Ophthalmology $1991 \mathrm{Feb}$; 98 (2):136-41.

32. Uusitalo MS, Van Quill KR, Scott IU, Matthay KK, Murray TG, O'Brien JM.: Evaluation of chemoprophylaxis in patients with unilateral retinoblastoma with high-risk features on histopathologic examination. Arch Ophthalmol. 2001 Jan; 119 (1):41-8.

33. Pena A, Howard SC et al: Impact of an education program on late diagnosis of retinoblastoma in Honduras. Pediatr Blood Cancer. 2006 Sep 28; [Epub ahead of print]. 